\title{
PATTERN OF FATAL BURN INJURY CASES- THREE YEARS STUDY AT A.M.C.H. MORTUARY
}

\author{
Nayan Mani Pathak1, Tarun Kumar Das², Rupak Kumar Gogoi ${ }^{3}$ \\ ${ }^{1}$ Assistant Professor, Department of Forensic Medicine, Assam Medical College and Hospital, Dibrugarh, Assam. \\ ${ }^{2}$ Associate Professor, Department of Forensic Medicine, Assam Medical College and Hospital, Dibrugarh, Assam. \\ 3Professor, Department of Forensic Medicine, Assam Medical College and Hospital, Dibrugarh, Assam.
}

ABSTRACT
BACKGROUND
Burn injury is one of the most important causes of death in India. Fire related burn is also a leading cause of disability and
disfigurement. It is usually seen that most of the victims are hailed from lower socio economic background. This study was
conducted to observe epidemiological factors relating to burn death so that preventive measures can be taken.
Study Design- It is an observational descriptive study.

\section{MATERIALS AND METHODS}

This study was conducted in the Department of Forensic Medicine, Assam Medical College \& Hospital, Dibrugarh, Assam from January 2013 to December 2015. All burn death cases which came for postmortem examination were included in the study. The data was obtained in predesigned proforma and analysed accordingly.

\section{RESULTS}

Majority of the victims were found to be female (509 cases, 83\%). Commonest age group was from 21 years to 30 years. During winter season (November to February) highest incidences occurred and majority of the victims were belonged to lower socio economic group. Majority of the victims died in hospital under treatment. (82.87\%) while $17.12 \%$ cases died on the spot or on the way to the hospital.

\section{CONCLUSION}

In our study it was noticed that majority of the victims were from lower socio economic group, illiterate and house wife and they usually use unsafe mode of source of fire for cooking and other purposes. Educating people by various means regarding fire hazards and safety measures and use of safe fire appliances will reduce the incidences of burn related injury and death.

\section{KEYWORDS}

Burn, Kerosene, Chula, Crime Scene, Dowry Death.

HOW TO CITE THIS ARTICLE: Pathak NM, Das TK, Gogoi RK. Pattern of fatal burn injury cases- three years study at A. M. C. H. mortuary. J. Evolution Med. Dent. Sci. 2017;6(57):4219-4221, DOI: 10.14260/Jemds/2017/915

\section{BACKGROUND}

Burn injuries are produced due to application of different forms of heat to body surface (External or internal) of which flame burn is the commonest cause. Fatality due to burn injury is one of the commonest cause of unnatural death in India. Fire related burn is also a leading cause of disability and disfigurement. In India and other developing countries, most of the burn injury cases found to be married, from lower socio economic group, illiterate, and lives in rural areas. At present scenario it is observed that burn injury is not only accidental but also it becomes a method used for doing suicide and homicide by some people. News of many cases of burn injury and death comes in newspaper or electronic media as burning the female by family members for dowry related matters. This study was conducted to observe and evaluate the incidences, age-sex distribution, socio economic as well as literacy status of the victims relating to burn death.

Financial or Other, Competing Interest: None.

Submission 05-05-2017, Peer Review 06-07-2017,

Acceptance 12-07-2017, Published 17-07-2017.

Corresponding Author:

Dr. Nayan Mani Pathak,

Assistant Professor,

Department of Forensic Medicine,

Assam Medical College and Hospital,

Dibrugarh, Assam.

E-mail: drnaypath@yahoo.com

DOI: $10.14260 /$ jemds $/ 2017 / 915$
The results of the study will reflect the causes and problems of burn injuries and it will help to reduce the number of incidences and proper management protocol and preventive measures can be designed which will be helpful for the society at large.

\section{Study Design}

It is an observational descriptive study.

\section{MATERIALS AND METHODS}

This study was conducted in the Department of Forensic Medicine, Assam Medical College \& Hospital, Dibrugarh, Assam during the period from January, 2013 to December, 2015. All burn death cases which came for postmortem examination were included in the study. The various data were collected from-

1. Documents supplied by the investigating officers namely inquest report, forwarding letter, dead body challan, photograph etc.

2. Hospital treatment records.

3. Interviewing the escorting police personals, family members, relatives, friends and neighbours of the deceased.

4. Postmortem examination.

The different data were obtained in predesigned proforma and thoroughly compiled, tabulated and analysed. The statistical analysis were discussed under various results 
and observations. The discussion was made and compared with similar works already done by other authors and various studies.

\section{RESULTS}

Out of 4144 medicolegal autopsy cases done during this period, 613 death were found be due to burn injury. The females are found to be common victim in this study comprising $83 \%$ (509 cases) of total cases studied.

\begin{tabular}{|c|c|}
\hline Sex & Number \\
\hline Male & $104(17 \%)$ \\
\hline Female & $509(83 \%)$ \\
\hline \multicolumn{2}{|c|}{ Table 1. Sex distribution } \\
\hline
\end{tabular}

It was observed that most of the victims were within the age group of 21 years to 30 years (46\%, 282 cases).

\begin{tabular}{|c|c|c|c|c|}
\hline Age (Years) & Male & Female & Total & $\mathbf{\%}$ \\
\hline $0-10$ & 1 & 06 & 7 & 1.14 \\
\hline $11-20$ & 08 & 91 & 99 & 16.15 \\
\hline $21-30$ & 43 & 239 & 282 & 46 \\
\hline $31-40$ & 32 & 100 & 132 & 21.53 \\
\hline $41-50$ & 08 & 45 & 53 & 08.65 \\
\hline $51-60$ & 07 & 20 & 27 & 04.40 \\
\hline $61-70$ & 05 & 08 & 13 & 2.12 \\
\hline \multicolumn{7}{|c}{ Table 2. Age wise distribution } \\
\hline
\end{tabular}

Most of the victims were found to be married $(82.22 \%$, 504 cases) out of which females being the majority (69.5\%, 426 cases).

\begin{tabular}{|c|c|c|c|c|}
\hline Marital Status & Male & Female & Total & \% \\
\hline Widow/er & 1 & 11 & 12 & 1.95 \\
\hline Unmarried & 25 & 72 & 97 & 15.82 \\
\hline Married & 78 & 426 & 504 & 82.22 \\
\hline \multicolumn{5}{|c|}{ Table 3. Marital Status } \\
\hline
\end{tabular}

As looked for religion, Hindus were found to be the commonest victims. (90.37\%, 554 cases).

\begin{tabular}{|c|c|c|c|c|}
\hline Religion & Male & Female & Total & \% \\
\hline Hindu & 95 & 459 & 554 & 90.37 \\
\hline Muslim & 6 & 33 & 39 & 06.36 \\
\hline Others & 0 & 02 & 02 & 0.33 \\
\hline \multicolumn{5}{|c|}{ Table 4. Religion } \\
\hline
\end{tabular}

The study showed $30.01 \%$ (184) cases found to be illiterate.

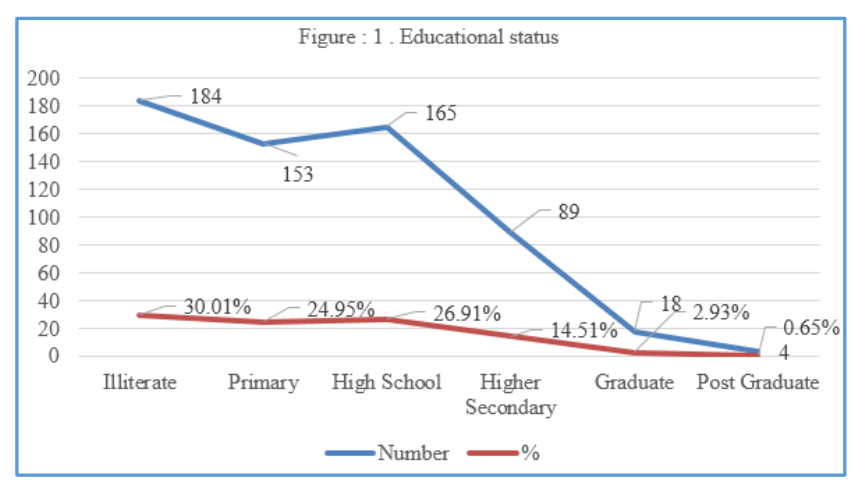

Housewives were the most common victims (45.35\%, 278 cases) followed by daily wedge earner (28.05\%, 172 cases).

\begin{tabular}{|c|c|c|c|}
\hline \multicolumn{2}{|c|}{ Occupation } & Number & \% \\
\hline \multirow{2}{*}{ Unemployed } & Housewife & 278 & 45.35 \\
\cline { 2 - 4 } & Others & 61 & 9.95 \\
\hline \multicolumn{2}{|c|}{ Daily wager } & 172 & 28.05 \\
\hline \multicolumn{2}{|c|}{ Farmer } & 09 & 1.47 \\
\hline \multicolumn{2}{|c|}{ Business } & 25 & 4.07 \\
\hline \multicolumn{2}{|c|}{ Private sector employee } & 43 & 7.01 \\
\hline \multicolumn{2}{|c|}{ Govt. sector employee } & 25 & 4.07 \\
\hline \multicolumn{2}{|c|}{ Table 5. Occupation } \\
\hline
\end{tabular}

People belonging to lower socio economic status group were found to be common victims (62.8\%, 385 cases).

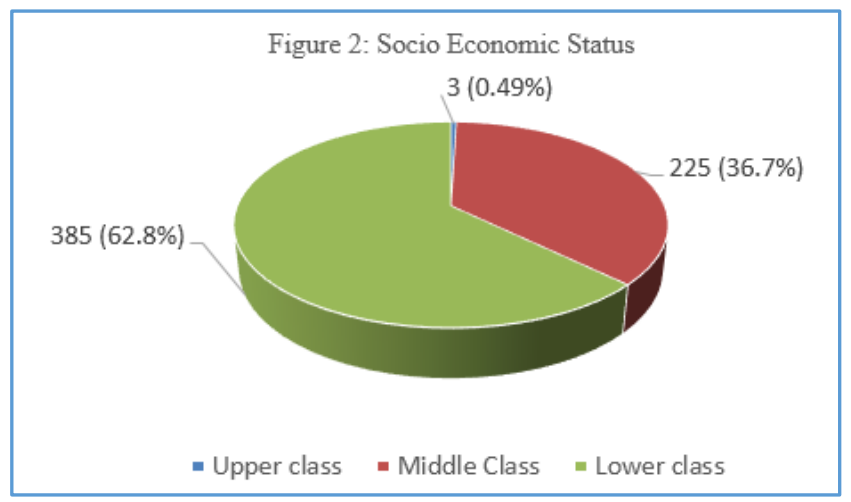

More number of cases seen in people living in rural areas (83.03\%, 509 cases) and lowest being in people living in urban areas $(6.69 \%, 41$ cases $)$.

\begin{tabular}{|c|c|c|}
\hline Locality & Total & \% \\
\hline Rural & 509 & 83.03 \\
\hline Semi urban & 63 & 10.28 \\
\hline Urban & 41 & 6.69 \\
\hline \multicolumn{2}{|c}{ Table 6: Locality } \\
\hline
\end{tabular}

Most of the incidences occurred during winter season, from November to February $(38.17 \%, 234$ cases).

\begin{tabular}{|c|c|c|}
\hline Season & Number & $\%$ \\
\hline Spring (March- May) & 175 & 28.55 \\
\hline Rainy (June- September) & 161 & 26.26 \\
\hline Autumn (October) & 43 & 7.01 \\
\hline Winter (November- February) & 234 & 38.17 \\
\hline
\end{tabular}

Maximum incidences occurred while inside house, specially in the kitchen during cooking process $(57.91 \%, 355$ cases).Commonest source of flame was kerosene oil (49.42\%, 303 cases) and followed by from using Chula (23.32\%, 143 cases). Maximum number of victims were found to be wearing synthetic garment during the incidence (54.97\%, 337 cases).Most of the victims died at hospital (82.87 \%, 508 cases) while 105 cases $(17.12 \%)$ died on spot or on the way to hospital. It was observed that most of the victims suffered burn injury over $80-90 \%$ of total body surface areas (25\%).

\section{DISCUSSION}

Incidences of burn related death in female is more common in India in the present scenario. Present study showed that females $(83 \%)$ are the commonest victims as compared to male (17\%). Sharma B.R, Harish D, Sharma S. also found female outnumbered male with 79.98\%.1 Memchoubi \& 
Nabachandra also mentioned similar findings. ${ }^{2}$ The commonest age group were in between 21 years to 30 years (46\%). Memchoubi \& Nabachandra also mentioned about this age group and they found $38.46 \% .^{2}$ Patel et al also reported that $33.75 \%$ cases were belonged to the $21-30$ years age group. ${ }^{3}$ Pandey S.K, Chaurasia N. did mention almost similar age group (46.00\%). ${ }^{4}$ Married females (69.5\%), housewives and those hailing from lower socio economic status (62.8\%) were most common victims. Mangal H.M., Pathak A. found 78\% married. ${ }^{5}$ Lal S., Yadav G.K., Gupta R. found similar findings. ${ }^{6}$ Memchoubi \& Nabachandra found $53.84 \%$ cases hailing from lower economic group. ${ }^{2}$ Incidences also found mostly in rural areas(83.03\%), using stoves and Chula with kerosene for cooking as well as for lighting lamps. Gupta et al found commonest source of flame to be kerosene oil (43.54\%).7 In a study by Lal S., Yadav G.K., Gupta R. found indigenous kerosene lamp was the commonest source of fire (33.03\%). ${ }^{6}$ Zopate P.R, Tirpude B.H. et al in their study obsereved $84.5 \%$ cases were from rural areas. ${ }^{8}$ Wearing garments plays important role in the incidences of burn injuries. Most of the victims in our study were found to be wearing synthetic garments (54.97\%). Bhardwaj S. D, Singha $\mathrm{U}$, found $46.5 \%$ cases wearing synthetic garments. ${ }^{9}$ Gowri $\mathrm{S}$, Naik V. A. et al mentioned $65 \%$ female victims were wearing synthetic cloths at the time of incidence. ${ }^{10}$ Major numbers of cases received treatments and subsequently died in hospital (82.87\%). Choudhury B. L, Yadav P, Kumar M found in their study that $72.46 \%$ burn victims were died in the hospital. ${ }^{11}$ Buchade D, Kukade H, Dere R found that $89.03 \%$ victims died in hospital. ${ }^{12}$ Karaddi $\mathrm{S}$ et al also found $78.37 \%$ cases of victims died in hospital. ${ }^{13}$ Involvement of body surface area plays the vital role in the outcome of burn related injuries. In our study we found that $25 \%$ of the victims had burn injury over $80-90 \%$ total body surface areas. Karaddi $\mathrm{S}$ et al found $21.63 \%$ victims having involvement of $80-90 \%$ burn of total body surface areas. ${ }^{13}$ Zanjad N. P, Godboli H. V. 41.4\% cases sustained more than $80 \%$ body surface areas. ${ }^{14}$

\section{CONCLUSION}

Burn injury is a major cause of not only loss of valuable human life but also lead to serious deformity and disfigurement causing people to suffer throughout their life. Educating people by various means regarding fire hazards and safety measures and use of safe fire appliances can reduce the incidents of burn related injuries, deformities and death. Incidences of burn death and deformity can also be reduced to some extent by treatment of the victims in modern burn care facilities. The manner of burn injury may be suicidal, accidental or homicidal; it is always difficult to determine and most of the time it is not possible to comment regarding the manner of death only by doing post-mortem examination. Therefore it will be helpful if crime scene examination by forensic expert is done prior to sending the body to the mortuary.

\section{REFERENCES}

[1] Sharma B.R., Harish D, Sharma A, Sharma S. Accidental fatal burns in Indian kitchen: Are they really accidental? Journal of Indian Association of Forensic Medicine. 2006; 28(1): 14-17.

[2] Memchoubi Ph., Nabachandra H. A study of burn death in Imphal. Journal of Indian Academy of Forensic Medicine. 2007; 29(4): 131-134.

[3] Patel et al. Epidemiological study of fatal burn cases brought for post-mortem examination at Mortuary of Sir Takhtsingi General Hospital, Bhavanagar. International Journal of Res. Med. 2015; 4(1): 113116.

[4] Pandey S.K., Chaurasia N. Thermal burn: An epidemiological retrospective study. Journal of Punjab Academy of Forensic Medicine \& Toxicology. 2014; 14(1): 15-18

[5] Mangal H.M., Pathak A. The fire is both- A blessing and scourge to the mankind. Journal of Indian Academy of Forensic Medicine. 2007; 29(4): 75-77.

[6] Lal S., Yadav G.K., Gupta R. Mortality pattern of burn patient admitted in S.G.M. hospital, Rewa, A teaching institute of central India. Journal of Sci SOC. 2012; 39: 130-135.

[7] Gupta et al. Profile of the fatal burn death from the Varanashi region, india. Journal of Clinical \& Diagnostic research. 2012; 6(4): 608-611.

[8] Zopate P.R, Tirpude B.H, Markey P.N. Pattern of burn injury in rural parts of central India. Indian journal of Burn. 2011; 19(1): 36-42.

[9] Bhardwaj S.D, Singha U. An epidemiological survey of burn injuries in rural areas, Bhopal- A cross sectional study. Indian journal of Burn. 2012; 20(1): 62-65.

[10] Gowri S, Naik V.A, Powar R. Epidemiology and outcome of burn injuries. Journal of Indian Academy of Forensic Medicine. 2012; 34(4): 12-14.

[11] Choudhary B. L, Yadav P, Kumar M. Mortuary profile of burn injuries: A postmotem study in Lady hardinge Medical College, New Delhi. Journal of Indian Academy of Forensic Medicine. 2013; 35(2): 123-124.

[12] Buchade D, Kukade H, Dere R. Pattern of burn cases brought to morgue, Scion hospital, Mimbai- A two year study. Journal of Indian Academy of Forensic Medicine. 2011; 33(4): 309-310.

[13] Karaddi S. et al. Study of death due to thermal in and around Gulbargh city. International Journal Med. Pharma. Sc. 2013; 03(11): 11-16.

[14] Zanjad N.P., Godboli H.V. Study of fatal burn cases in Medicolegal Autopsy. Journal of Indian Academy of Forensic Medicine. 2007; 29(3): 42-49. 